\title{
Association between iron status and thyroid function in Nepalese children
}

\author{
Saroj Khatiwada ${ }^{*}$, Basanta Gelal ${ }^{2}$, Nirmal Baral ${ }^{2}$ and Madhab Lamsal ${ }^{2}$
}

\begin{abstract}
Background: Deficiencies of iodine and iron may have adverse effect on thyroid function. This study was undertaken to investigate the association between iron status and thyroid function in Nepalese children living in hilly regions.

Methods: A cross-sectional study was conducted among 227 school children aged 6-12 years living in hilly regions of eastern Nepal. Urine and blood samples were analyzed for urinary iodine concentration, free thyroxine, free triiodothyronine, thyroid stimulating hormone, hemoglobin, serum iron and total iron binding capacity, and percentage transferrin saturation was calculated.

Results: The cohort comprised euthyroid $(80.6 \%, n=183)$, overt hypothyroid $(1.3 \%, n=3)$, subclinical hypothyroid $(16.3 \%, n=37)$ and subclinical hyperthyroid $(1.8 \%, n=4)$ children respectively. About $35.2 \%(n=80)$ children were anemic, $43.6 \%(n=99)$ were iron deficient and $19.8 \%(n=45)$ had urinary iodine excretion $<100 \mu \mathrm{g} / \mathrm{L}$. Hypothyroidism (overt and subclinical) was common in anemic and iron deficient children. The relative risk of having hypothyroidism (overt and subclinical) in anemic and iron deficient children was 5.513 (95 \% Cl: 2.844-10.685, $p<0.001$ ) and 1.939 ( $95 \%$ Cl: 1.091-3.449, $p=0.023$ ) respectively as compared to non-anemic and iron sufficient children. Thyroid stimulating hormone had significant negative correlation with hemoglobin $(r=-0.337, p<0.001)$ and transferrin saturation ( $r=-0.204, p=0.002)$.

Conclusions: Thyroid dysfunction, iron deficiency and anemia are common among Nepalese children. In this cohort, anemic and iron deficient children had poor thyroid function.
\end{abstract}

Keywords: Anemia, Iron deficiency, Nepal, School children, Thyroid dysfunction, Thyroid hormone

\section{Background}

Multiple micronutrient deficiencies are still a major public health problem faced by developing countries. Such deficiencies have adverse effects on growth and development, especially in vulnerable groups like pregnant women and children [1]. Deficiencies of trace elements like iodine, iron, zinc and selenium also impairs thyroid function [2]. Thyroid hormones influence a number of metabolic pathways and physiological components. Excess thyroid hormones cause hyperthyroidism whereas deficiency causes hypothyroidism [3]. Iodine deficiency and iron deficiency are considered as the most common cause of preventable brain damage and anemia respectively in developing countries like Nepal $[4,5]$. Anemia and iron deficiency have been found to be highly prevalent among Nepalese school

\footnotetext{
* Correspondence: khatiwadasaroj22@gmail.com

${ }^{1}$ Department of Biochemistry, Modern Technical College, Lalitpur, Nepal Full list of author information is available at the end of the article
}

children, whereas iodine nutrition has been continuously improving in school children [6, 7]. Iron deficiency with or without anemia affects child development and also has multiple adverse effects on thyroid metabolism $[8,9]$.

Studies have reported the association of thyroid function with iron status [10-12]. In the study by Metwalley et al. in Egypt, it was found that primary school children with iron deficiency anemia were liable to develop subclinical hypothyroidism and intellectual dysfunction [12]. Since, iron deficiency and anemia are highly prevalent in the Nepalese population, assessment of thyroid function in such a population may help to determine the potential effects of iron deficiency on thyroid metabolism [6]. Thyroid dysfunction has been also been reported more frequently in Nepalese population although iodine nutrition has been improving continuously $[13,14]$. It is however, unknown about the factors responsible for thyroid disorders in this region. It has been hypothesized that iron deficiency 
negatively affects thyroid function leading to increased rate of thyroid disorders [10]. Thus, there might be potential link between iron deficiency and thyroid dysfunction in this population as well. Taking in to account of poor iron status and higher rates of thyroid dysfunction in Nepalese population, we tried to find the possible effects of iron deficiency on thyroid function in Nepalese children by conducting the present study.

Specifically, we selected school children aged 6-12 years randomly from hilly regions of eastern Nepal and analyzed urine and blood samples to assess iodine status, iron status and thyroid function, and determine their association.

\section{Methods}

A cross-sectional study was conducted among children of two hilly districts (Sankhuwasabha and Dhankuta) of eastern Nepal in 2014. We assessed iodine status, iron status and thyroid function to find the association between iron status and thyroid function in the cross sectional population. Six schools (three schools in each district) were picked randomly and school children aged 6-12 years whose parents gave consent were enrolled randomly in the study. A total of 227 children (124 from Sankhuwasabha and 103 from Dhankuta district) were selected for the study. The ethical clearance for this study was given by the Institutional Review Board of B P Koirala Institute of Health Sciences (BPKIHS), Dharan. Sample size estimation was done on the basis of approximate prevalence of iodine deficiency $(15 \%)$, iron deficiency $(30 \%)$ and thyroid dysfunction $(20 \%)$ in Nepalese children.

Demographic variables (age, gender), urine samples $(10 \mathrm{ml})$ and venous blood samples $(3 \mathrm{ml})$ were collected from each child. The samples were transported to biochemistry laboratory of B P Koirala Institute of Health Sciences under refrigeration. Hemoglobin $(\mathrm{Hb})$ was measured within $24 \mathrm{~h}$ of sample collection by cyanmethemoglobin method, whereas other parameters were estimated within a week of sample collection [15]. Urinary iodine excretion (UIE) was measured by using ammonium persulphate digestion method (APDM) [16]. Serum iron and total iron binding capacity (TIBC) were measured by colorimetric methods using commercial kits (Roche Diagnostics). Transferrin saturation was calculated using serum iron and TIBC value [17]. Thyroid hormones (free triiodothyronine (fT3), free thyroxine (fT4) and thyroid stimulating hormone (TSH)) were measured by immunoassay methods using ELISA kits from HUMAN Diagnostics. Normal reference range provided by kits for serum iron was 37-145 $\mu \mathrm{g} / \mathrm{dl}$ for women and 59-158 $\mu \mathrm{g} / \mathrm{dl}$ for men and $274-385 \mu \mathrm{g} / \mathrm{dl}$ for TIBC. Similarly the normal reference range for thyroid hormones were fT3 $(1.4-4.2 \mathrm{pg} / \mathrm{ml})$, fT4 (0.8-
$2.2 \mathrm{ng} / \mathrm{dl})$ and TSH $(0.39-6.16 \mathrm{mIU} / \mathrm{L})$ according to kit provider.

The data generated from the study were entered in msexcel and analyzed using SPSS version 19 software. Continuous variables were expressed as mean \pm SD, except for UIE and TSH (expressed as median) and categorical variables as number (percentage). Independent $t$ test, one way ANOVA, Man whitney test and Kruskal Wallis test was applied for continuous variables and chi-square test for categorical variables at $95 \%$ confidence interval. Pearson correlation and Spearman's rho correlation analysis was done among variables to see the association between iron status indicator and thyroid hormones at $95 \%$ confidence interval. Relative risk for hypothyroidism in anemic and iron deficient as compared to non-anemic and iron sufficient was calculated at $95 \%$ confidence interval.

\section{Results}

Among the study population, $55.5 \%(n=126)$ were males and $44.5 \%(n=101)$ were females. The median UIE and TSH with IQR was $222 \mu \mathrm{g} / \mathrm{L}(121 \mu \mathrm{g} / \mathrm{L} ; 296 \mu \mathrm{g} / \mathrm{L})$ and 4.0 $\mathrm{mIU} / \mathrm{L}(2 \mathrm{mIU} / \mathrm{L} ; 6 \mathrm{mIU} / \mathrm{L})$ respectively. The mean level of $\mathrm{Hb}$, serum iron, TIBC, transferrin saturation, fT3, fT4 and TSH were $12.2 \pm 1.9 \mathrm{gm} / \mathrm{dl}, 70.5 \pm 35.4 \mu \mathrm{g} / \mathrm{dl}, 382.8 \pm$ $89.5 \mu \mathrm{g} / \mathrm{dl}, 20.1 \pm 12.6 \%, 2.7 \pm 0.8 \mathrm{pg} / \mathrm{ml}, 1.2 \pm 0.4 \mathrm{ng} / \mathrm{dl}$ and $4.4 \pm 2.8 \mathrm{mIU} / \mathrm{L}$ respectively in the study population, which are all in normal range. No significant differences in UIE $(p=0.98), \mathrm{Hb}(p=0.078)$, serum iron $(p=0.594)$, TIBC $(p=0.781)$, transferrin saturation $(p=0.766)$, fT3 $(p=0.912)$, fT $4(p=0.842)$ and TSH $(p=0.383)$ were observed among gender. On the basis of $\mathrm{Hb}$ cutoff value for anemia for different age group and transferrin saturation cutoff $<16$ for iron deficiency, $35.2 \%(n=80)$ and $43.6 \%(n=99)$ children were anemic and iron deficient respectively [18]. About, $19.8 \%$ $(n=45)$ children had UIE $<100 \mu \mathrm{g} / \mathrm{L}$, which is considered as iodine deficiency on the basis of $\mathrm{WHO}$ criteria for iodine status [19]. Level of biochemical parameters according to anemia and iron status is shown in Table 1. Median TSH level was higher in anemic than non-anemic $(p<0.001)$, but similar in iron deficient and iron sufficient $(p=0.05)$. fT3 was significantly higher in iron sufficient than iron deficient $(p=0.003)$. Level of $\mathrm{Hb}$, serum iron, TIBC and transferrin saturation was $12.3 \pm 2.1 \mathrm{gm} / \mathrm{dl}$ versus $12.3 \pm 1.9 \mathrm{gm} / \mathrm{dl} \quad(p=0.924), 81.4 \pm 35.9 \mu \mathrm{g} / \mathrm{dl}$ versus $67.9 \pm 34.9 \mu \mathrm{g} / \mathrm{dl}(p=0.022), 371.7 \pm 97.5 \mu \mathrm{g} / \mathrm{dl}$ versus $385.6 \pm 87.6 \mu \mathrm{g} / \mathrm{dl} \quad(p=0.354)$, and $23.8 \pm 12.8 \%$ versus $19.3 \pm 12.5 \%(p=0.032)$ among iodine deficient and iodine sufficient children respectively. Similarly, the mean level of fT3, fT4 and median TSH was $2.8 \pm 0.9 \mathrm{pg} / \mathrm{ml}$ versus $2.7 \pm$ $0.8 \mathrm{pg} / \mathrm{ml}(p=0.78) ; 1.2 \pm 0.5 \mathrm{ng} / \mathrm{dl}$ versus $1.2 \pm 0.4 \mathrm{ng} / \mathrm{dl}$ $(p=0.567)$ and $4.0 \mathrm{mIU} / \mathrm{L}(2 ; 6)$ versus $4.0 \mathrm{mIU} / \mathrm{L}(2 ; 6)$ $(p=0.953)$ among iodine deficient and iodine sufficient respectively. 
Table 1 Biochemical parameters in study population according to anemia and iron status

\begin{tabular}{|c|c|c|c|c|c|c|c|}
\hline \multirow[t]{3}{*}{ Variables } & \multirow{3}{*}{$\begin{array}{l}\text { Total } \\
N=227\end{array}$} & \multicolumn{3}{|l|}{ Anemia status } & \multicolumn{3}{|l|}{ Iron status } \\
\hline & & \multirow{2}{*}{$\begin{array}{l}\text { Anemic } \\
N=80\end{array}$} & \multirow{2}{*}{$\begin{array}{l}\text { Non-anemic } \\
N=147\end{array}$} & \multirow[t]{2}{*}{$P$ value } & \multirow{2}{*}{$\begin{array}{l}\text { Iron deficient } \\
N=99\end{array}$} & \multirow{2}{*}{$\begin{array}{l}\text { Iron sufficient } \\
N=128\end{array}$} & \multirow[t]{2}{*}{$P$ value } \\
\hline & & & & & & & \\
\hline $\mathrm{UIE}(\mu \mathrm{g} / \mathrm{L})$ & $222(121 ; 296)$ & $225(112.7 ; 303.5)$ & $222(125 ; 281)$ & 0.788 & $228(133 ; 307)$ & $220(119.5 ; 291)$ & 0.428 \\
\hline Hemoglobin (gm/dl) & $12.2 \pm 1.9$ & $10.3 \pm 1.0$ & $13.3 \pm 1.3$ & $<0.001$ & $11.6 \pm 1.8$ & $12.7 \pm 1.7$ & $<0.001$ \\
\hline Serum iron $(\mu \mathrm{g} / \mathrm{dl})$ & $70.5 \pm 35.4$ & $55.4 \pm 21.8$ & $78.8 \pm 38.6$ & $<0.001$ & $39.6 \pm 12.9$ & $94.4 \pm 28.1$ & $<0.001$ \\
\hline $\operatorname{TIBC}(\mu \mathrm{g} / \mathrm{dl})$ & $382.8 \pm 89.5$ & $414.6 \pm 81.5$ & $365.4 \pm 89.2$ & $<0.001$ & $433.2 \pm 81.9$ & $343.8 \pm 74.8$ & $<0.001$ \\
\hline Transferrin saturation (\%) & $20.1 \pm 12.6$ & $14.2 \pm 7.6$ & $23.4 \pm 13.6$ & $<0.001$ & $9.2 \pm 2.5$ & $28.6 \pm 10.7$ & $<0.001$ \\
\hline Free T3 (pg/ml) & $2.7 \pm 0.8$ & $2.6 \pm 0.9$ & $2.8 \pm 0.7$ & 0.13 & $2.6 \pm 0.8$ & $2.9 \pm 0.7$ & 0.003 \\
\hline Free T4 (ng/dl) & $1.2 \pm 0.4$ & $1.2 \pm 0.5$ & $1.2 \pm 0.4$ & 0.526 & $1.2 \pm 0.5$ & $1.2 \pm 0.4$ & 0.531 \\
\hline TSH (mIU/L) & $4.0(2 ; 6)$ & $5.0(3 ; 8)$ & $3.0(2 ; 5)$ & $<0.001$ & $4.0(3 ; 7)$ & $4.0(2 ; 6)$ & 0.05 \\
\hline
\end{tabular}

The data is expressed as mean \pm SD except for UIE and TSH (expressed as median with IQR). $P$ value was calculated at $95 \%$ confidence interval

Among the study children, $80.6 \%(n=183), 1.3 \%(n=3)$, $16.3 \%(n=37)$ and $1.8 \%(n=4)$ were euthyroid, overt hypothyroid, subclinical hypothyroid and subclinical hyperthyroid respectively. Thyroid status according to anemia and iron deficiency is shown in Table 2. Similarly, level of $\mathrm{UIE}, \mathrm{Hb}$ and iron status indicators in the study population according to thyroid function status is shown in Table 3. No significant difference in number of euthyroid (36 versus $147, p=1.0$ ), overt hypothyroid ( 2 versus $1, p=0.101$ ), subclinical hypothyroid (7 versus $30, p=1.0)$ and subclinical hyperthyroid ( 0 versus $4, p=0.587)$ was observed among iodine deficient and iodine sufficient children.

A significant positive correlation was observed between $\mathrm{Hb}$ level and transferrin saturation $(r=0.411$, $p=<0.001)$. Correlation of $\mathrm{Hb}$ and transferrin saturation with TSH level is shown in Figs. 1 and 2 respectively. Transferrin saturation was significantly negatively correlated with TSH $(r=-0.204, p=0.002)$, positively with fT3 $(r=0.13, p=0.051)$ and weakly negatively with fT4 $(r=-0.089, p=0.182)$. Similarly, $\mathrm{Hb}$ was significantly negatively correlated with $\mathrm{TSH}$ $(r=-0.337, p<0.001)$, but weakly correlated with fT3 $(r=0.077, p=0.249)$ and fT4 $(r=-0.018, p=0.787)$. UIE was very weakly correlated with TSH $(r=0.031$, $p=0.643)$, fT3 $(r=-0.014, p=0.832)$ and fT4 $(r=$ $0.047, p=0.484)$. The risk of having hypothyroidism (overt and subclinical) in anemic and iron deficient children was 5.513 (95\% CI: 2.844-10.685, $p<0.001$ ) and 1.939 (95 \% CI: $1.091-3.449, p=0.023$ ) respectively as compared to non-anemic and iron sufficient children.

\section{Discussion}

Iodine and iron deficiencies are very common in the regions where adequate iodine and iron is not present in normal diet [20]. We observed anemia and iron deficiency in $35.2 \%$ and $43.6 \%$ children respectively. Anemia and iron deficiency have been found highly prevalent in Nepalese school children. Study by Khatiwada et al. reported anemia and iron deficiency in $34.5 \%$ and $43.4 \%$ school children respectively [6]. The anemia prevalence according to Nepal demographic and health survey, Baral et al. study and Khatiwada et al. study were $48 \%$ (among age 6-59 months), $65.6 \%$ (among age 10-19 years) and 37.9\% (among age 4-13 years) respectively [7]. Iron deficiency has been considered as the most common cause of anemia in developing countries [18]. Our findings further support that iron deficiency is the most common cause for anemia in Nepalese children as indicated by poor iron status indicators in anemic children. Besides the lack of adequate iron in diet, other chronic conditions like hook worm infestation, malaria and genetic factors also contribute to high prevalence of anemia in developing countries [18].

Table 2 Thyroid function status in study population according to anemia and iron status

\begin{tabular}{|c|c|c|c|c|c|c|c|}
\hline \multirow[t]{3}{*}{ Variables } & \multirow{3}{*}{$\begin{array}{l}\text { Total } \\
N=227\end{array}$} & \multicolumn{3}{|c|}{ Anemia status } & \multicolumn{3}{|l|}{ Iron status } \\
\hline & & \multirow{2}{*}{$\begin{array}{l}\text { Anemic } \\
N=80\end{array}$} & \multirow{2}{*}{$\begin{array}{l}\text { Non-anemic } \\
N=147\end{array}$} & \multirow[t]{2}{*}{$P$ value } & \multirow{2}{*}{$\begin{array}{l}\text { Iron deficient } \\
N=99\end{array}$} & \multirow{2}{*}{$\begin{array}{l}\text { Iron sufficient } \\
N=128\end{array}$} & \multirow[t]{2}{*}{$P$ value } \\
\hline & & & & & & & \\
\hline Euthyroidism, n (\%) & $183(80.6 \%)$ & $49(21.6 \%)$ & $134(59 \%)$ & $<0.001$ & $72(31.7 \%)$ & $111(48.9 \%)$ & 0.011 \\
\hline Overt hypothyroidism, n (\%) & $3(1.3 \%)$ & $3(1.3 \%)$ & - & 0.043 & $3(1.3 \%)$ & - & 0.082 \\
\hline Subclinical hypothyroidism, n (\%) & $37(16.3 \%)$ & $27(11.9 \%)$ & $10(4.4 \%)$ & $<0.001$ & $21(9.3 \%)$ & $16(7 \%)$ & 0.102 \\
\hline Subclinical hyperthyroidism, n (\%) & $4(1.8 \%)$ & $1(0.4 \%)$ & $3(1.3 \%)$ & 1.0 & $3(1.3 \%)$ & $1(0.4 \%)$ & 0.32 \\
\hline
\end{tabular}

The data is expressed as number (percentage). $P$ value was calculated at $95 \%$ confidence interval 
Table 3 Biochemical parameters in study population according to thyroid function

\begin{tabular}{lllll}
\hline Variables & Euthyroid & Hypothyroid* & \multicolumn{2}{l}{$\begin{array}{l}\text { Subclinical hyperthyroid } \\
N=4\end{array}$} \\
& $N=183$ & $N=40$ & $219(141.7 ; 295.5)$ & 0.345 \\
UIE $(\mu \mathrm{g} / \mathrm{L})$ & $213(120 ; 290)$ & $236.5(155.5 ; 301.5)$ & $13.9 \pm 2.5$ & $<0.001$ \\
Hemoglobin $(\mathrm{gm} / \mathrm{dl})$ & $12.6 \pm 1.7$ & $10.7 \pm 2.0$ & $50.5 \pm 23.3$ & 0.012 \\
Serum iron $(\mu \mathrm{g} / \mathrm{dl})$ & $74.0 \pm 36.7$ & $57.0 \pm 26.6$ & $393.4 \pm 101.1$ & 0.018 \\
TIBC $(\mu \mathrm{g} / \mathrm{dl})$ & $374.7 \pm 84.2$ & $418.8 \pm 104.8$ & $14.0 \pm 8.7$ & 0.004 \\
Transferrin saturation $(\%)$ & $21.5 \pm 13.2$ & $14.6 \pm 8.1$ & \\
\hline
\end{tabular}

The data is expressed as mean \pm SD except for UIE (expressed as median with IQR). Asterik $\left(^{*}\right)$ indicates that hypothyroid group included both overt and subclinical hypothyroid. $P$ value was calculated at $95 \%$ confidence interval

Though, the median UIE $(222 \mu \mathrm{g} / \mathrm{L})$ in our study population was more than optimum, we found $19.8 \%$ children had insufficient UIE, which is considered as iodine deficiency [19]. Our results suggest improvement on iodine status in Nepalese children. Higher median UIE than optimum as seen in our study also indicates excessive iodine intake and raises concern about the risk for iodine-induced hyperthyroidism [21]. The median UIE in the present study was slightly lower than in our previous study in Terai region where median UIE was $226.3 \mu \mathrm{g} / \mathrm{L}$, but higher than in remote hilly regions where we reported median UIE of $187.52 \mu \mathrm{g} / \mathrm{L}$ [21, 22]. Since, soils in hills and mountains are reported to lack sufficient iodine and thus in the food derived from them, continuous provision of adequately iodized salt in such areas is necessary. Both, excess or insufficient intake of iodine adversely affects thyroid health, so optimum iodine intake should be maintained [23].

Present study reveals subclinical hypothyroidism (16.3\%) as the commonest thyroid dysfunction in Nepalese school children followed by overt hypothyroidism (1.3\%) and subclinical hyperthyroidism (1.8\%). In one community based study among school children in eastern Nepal, Chaudhari et al. reported that $31.8 \%$ and $29.5 \%$ children had subclinical hypothyroidism in Sunsari and Dhankuta districts respectively. However they did not reported any overt hypothyroidism or subclinical hyperthyroidism [24]. Study by Baral et al. at a hospital in eastern Nepal reported that $13.6 \%$ population had hyperthyroidism and $17.1 \%$ had hypothyroidism [13]. Previous studies in chronic disease patients like diabetes mellitus and chronic kidney diseases in eastern Nepal have reported thyroid dysfunction particularly subclinical hypothyroidism in large part of study patients $[25,26]$. The high rate of hypothyroidism in the study subjects may be due to high rate of thyroid autoimmunity and deficiency of micronutrients like iron [25]. The most common cause of thyroid disorders worldwide is iodine deficiency, leading to goitre formation and hypothyroidism. In iodine-replete areas, most persons with thyroid disorders have autoimmune diseases

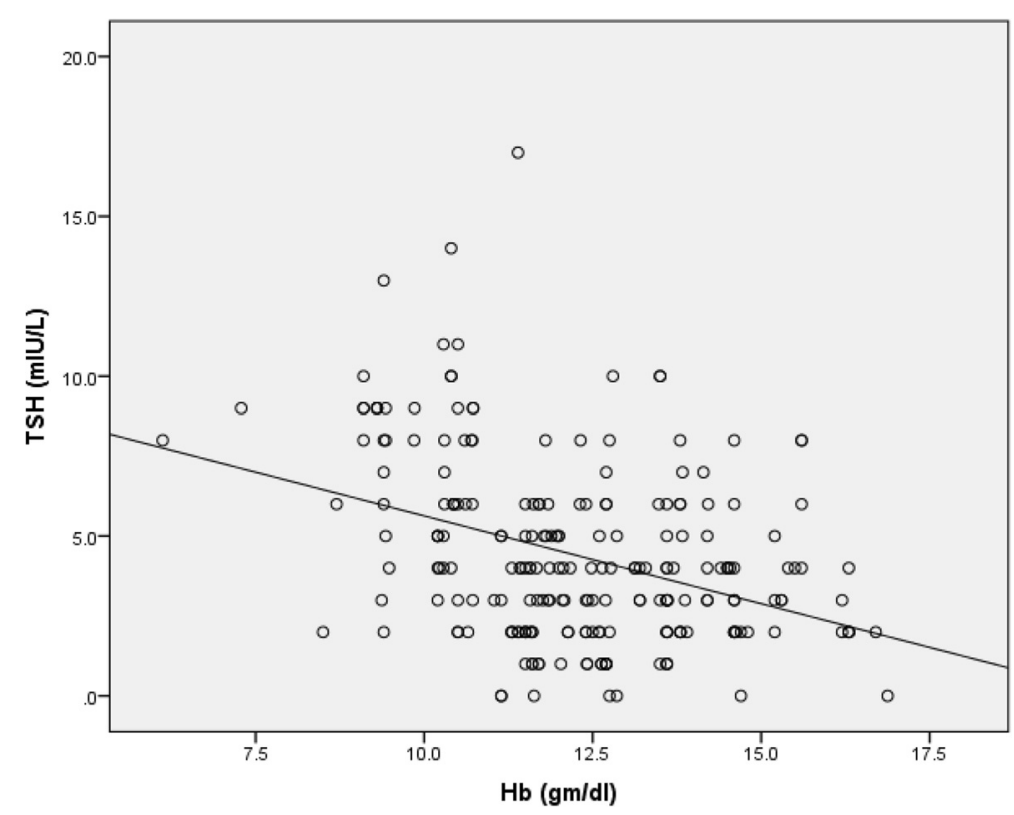

Fig. 1 Correlation between TSH level and Hb level 


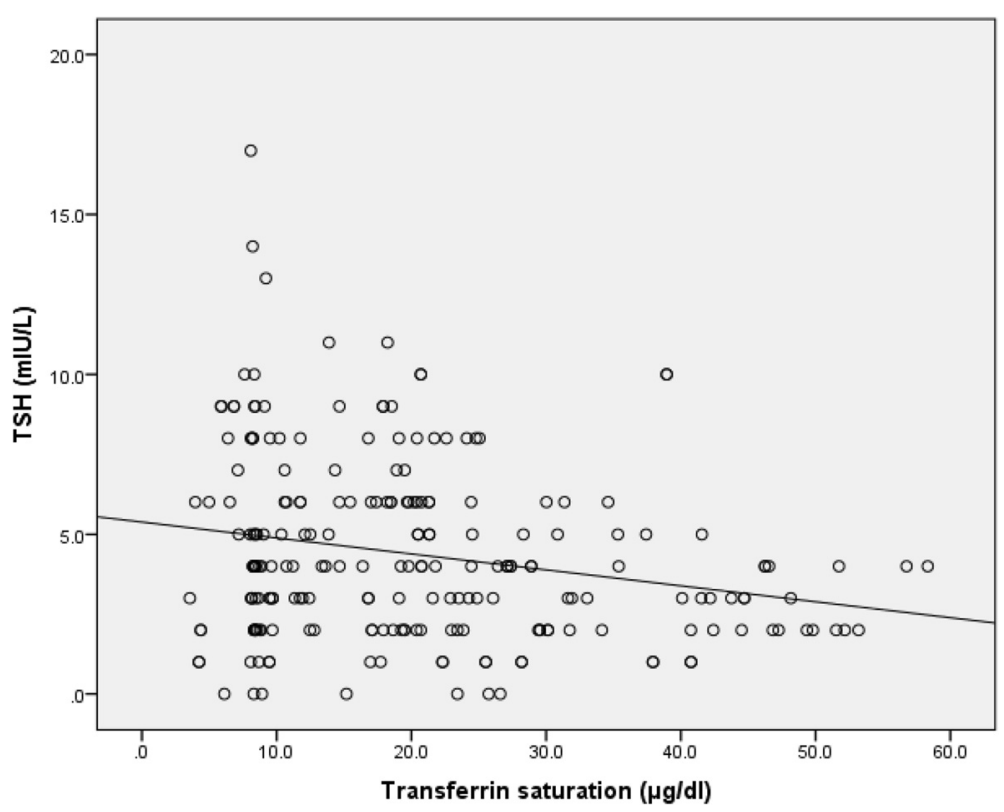

Fig. 2 Correlation between TSH level and transferrin saturation

like hashimoto's thyroiditis and Graves' disease [27]. The present study reveals no difference in thyroid function among iodine deficient and iodine sufficient children, and no association between UIE and thyroid hormones. Previous studies have also reported that there are usually no, or weak, associations between UIE and thyroid hormone concentrations [28].

In the present study, we observed significantly lower $\mathrm{Hb}$ level and iron status indicators in hypothyroids (overt and subclinical) than euthyroids, and iron deficiency and anemia in larger fraction of hypothyroid (both overt and subclinical) children. Our findings are in accord to results of previous studies by Bremner et al. and Banday et al. $[29,30]$. Bremner et al. found serum iron concentrations significantly lower in participants with subclinical hypothyroidism than euthyroid subjects $(p=0.001)$, and Banday et al. reported iron deficiency in a significant portion of patients with primary hypothyroidism $[29,30]$. It is believed that thyroid diseases affect the process of hematopoiesis and thyroid hormone deficiency may lead to bone marrow repression and/or decrease in erythropoietin production due to the reduction of $\mathrm{O}_{2}$ requirements. Thyroid hormones have also found to regulate the gene expression of transferrin [31].

Our findings suggest that anemic subjects tend to have higher TSH than non-anemic subjects, however, fT3 and fT4 does not seem to differ. Similarly, we observed that iron deficient children had significantly lower fT3 level than iron sufficient children. In a study by Metwalley et al., iron deficient children with hemoglobin level 10.9-7 $\mathrm{gm} / \mathrm{dl}$ had significantly higher levels of serum fT3 and fT4 $(p<0.01$ for both) and significantly lower levels of serum TSH $(p<0.05)$ as compared to patients with $\mathrm{Hb}$ level $<7 \mathrm{gm} / \mathrm{dl}$ [12]. In another study in Bangladesh among general population, serum TSH level was significantly higher $(p<0.05)$ and serum $\mathrm{fT} 4$ was significantly lower $(p<0.05)$ in iron deficient subjects than healthy controls, however, serum fT3 was almost similar between iron deficient and healthy controls [32]. Our finding demonstrates that anemic and iron deficient children have high risk for hypothyroidism, and hypothyroidism is associated with anemic and iron deficient children. Thus our findings suggests for the possibility that iron deficiency might impair thyroid metabolism as reported in previous studies. The two initial steps of thyroid hormone synthesis are catalyzed by heme containing enzyme, thyroid peroxidase. Severe iron deficiency may lower thyroid peroxidase activity and interfere with the synthesis of thyroid hormones thereby leading to hypothyroidism [33]. Studies have revealed that iron deficiency anemia (IDA) impairs thyroid metabolism and also decreases plasma total T4 and T3 concentrations and reduces peripheral conversion of T4 to T3 [9].

In the present study, we observed negative relation of transferrin saturation and $\mathrm{Hb}$ with TSH. Previous study by Bremner et al. reported significant relationships between free $\mathrm{T} 3$ and $\mathrm{Hb}$, and inverse relationship of TSH with serum iron and transferrin saturation [29]. Bivolarska et al. also found slight positive statistically significant correlative association between the levels of free $\mathrm{T} 4$ and $\mathrm{Hb}(r=0.217, p=0.033)$ [11]. While many studies have found that both iron metabolism and thyroid functions are interdependent and each one of them could have a regulatory role, some studies have reported 
no association between thyroid hormones and anemia or iron deficiency [31-34]. In the study in Bangladesh, Akhter et al. observed no significant correlation of $\mathrm{Hb}$ concentration with serum TSH, fT3 and fT4 concentrations both in iron deficient and healthy control group [32]. Similarly, in the study in an area of mild iodine deficiency in Turkey, thyroid hormone levels of children with anemia were not significantly different from those without anemia, and there was no significant correlation between thyroid hormones and iron status [34]. There are several limitations of the present study. The sample size was small. Also, because of its cross-sectional nature we cannot draw conclusion about cause and effect relation between iron deficiency and thyroid dysfunction. Since, anti-thyroid peroxidase antibody (anti-TPO) was not assayed in the population, high prevalence of thyroid autoimmunity may also contribute for high rate of thyroid dysfunction in the study population.

\section{Conclusions}

The study finds high prevalence of thyroid dysfunction, anemia and iron deficiency among Nepalese children and a significant association between iron status and thyroid function. Thus, anemia and iron deficiency seems to be associated with thyroid dysfunction particularly hypothyroidism. Future studies should be done in large samples and be directed toward finding the reasons for low thyroid hormones in anemic and iron deficient children.

\section{Abbreviations \\ Anti-TPO: Anti-thyroid peroxidase antibody; APDM: Ammonium persulphate digestion method; Free T3: Free triiodothyronine; Free T4: Free thyroxine; Hb: Hemoglobin; IDA: Iron deficiency anemia; TIBC: Total iron binding capacity; TSH: Thyroid stimulating hormone; UIE: Urinary iodine excretion.}

\section{Competing interests}

The authors declare that they have no competing interests.

\section{Authors' contributions}

SK, BG, NB and ML designed the study. SK performed laboratory analysis and wrote manuscript. BG, NB and ML reviewed manuscript. All authors read and approved the final version of manuscript.

\section{Acknowledgements}

We kindly acknowledge Institute advisory authority of B P Koirala Institute of Health Sciences for the financial assistance.

\section{Source of funding}

This study was supported by Nepal India Corpus fund through the Institute Advisory Authority of B P Koirala Institute of Health Sciences (BPKIHS).

\section{Author details}

'Department of Biochemistry, Modern Technical College, Lalitpur, Nepal. 2Department of Biochemistry, B P Koirala Institute of Health Sciences, Ghopa, Dharan, Nepal.

Received: 4 December 2015 Accepted: 11 January 2016 Published online: 27 January 2016

\section{References}

1. Arlappa N, Laxmaiah A, Balakrishna N, Harikumar R, Kodavanti MR, Reddy $C G$, et al. Micronutrient deficiency disorders among the rural children of West Bengal, India. Ann Hum Biol. 2011:38(3):281-9.

2. Eftekhari MH, Eshraghian MR, Mozaffari-Khosravi H, Saadat N, Shidfar F. Effect of iron repletion and correction of iron deficiency on thyroid function in iron-deficient Iranian adolescent girls. Pak J Biol Sci. 2007;10(2):255-60.

3. Pucci E, Chiovato L, Pinchera A. Thyroid and lipid metabolism. Int J Obes Relat Metab Disord. 2000;24 Suppl 2:S109-12.

4. Kapil U. Health consequences of iodine deficiency. Sultan Qaboos Univ Med J. 2007;7(3):267-72.

5. Olivares M, Walter T, Hertrampf E, Pizarro F. Anaemia and iron deficiency disease in children. Br Med Bull. 1999:55(3):534-43.

6. Khatiwada S, Lamsal M, Gelal B, Gautam S, Nepal AK, Brodie D, et al. Anemia, Iron Deficiency and lodine Deficiency among Nepalese School Children. Indian J Pediatr. 2015. doi: 10.1007/s12098-015-1924-y.

7. Khatiwada S, Gelal B, Gautam S, Tamang MK, Shakya PR, Lamsal M, et al. Anemia among school children in eastern Nepal. J Trop Pediatr. 2015;61(3): 231-3. doi:10.1093/tropej/fmv016.

8. World Health Organization. Assessing the iron status of populations. $2^{\text {nd }} \mathrm{Ed}$. Geneva, Switzerland: World Health Organization/Centers for Disease Control and Prevention Technical Consultation on the Assessment of Iron Status at the Population Level; 2004. http://www.who.int/nutrition/publications/ micronutrients/anaemia_iron_deficiency/9789241596107.pdf.

9. Hess SY, Zimmermann MB, Arnold M, Langhans W, Hurrell RF. Iron deficiency anemia reduces thyroid peroxidase activity in rats. J Nutr. 2002; 132(7):1951-5.

10. Kammal M, Abdrabo AA. Assessment of thyroid hormone levels in Sudanese females with iron deficiency. Sudan Med J. 2014;50(2):98-102.

11. Bivolarska A, Gatseva P, Maneva A. Association between thyroid and iron status of pregnant women in Southern Bulgaria. J Endocrinol Diabetes Mellit. 2013;1:15-21.

12. Metwalley KA, Farghaly HS, Hassan AF. Thyroid status in Egyptian primary school children with iron deficiency anemia: Relationship to intellectual function. Thyroid Res Pract. 2013;10:91-5.

13. Baral N, Lamsal M, Koner BC, Koirala S. Thyroid dysfunction in eastern Nepal. Southeast Asian J Trop Med Public Health. 2002;33:638-41.

14. Nepal AK, Khatiwada S, Shakya PR, Gelal B, Lamsal M, Brodie D, et al. lodine status after iodized salt supplementation in school children of eastern Nepal. Southeast Asian J Trop Med Public Health. 2013;44(6):1072-8.

15. Bain BJ, Lewis SM, Bates I. Basic haematological techniques. In: Lewis SM, Bain BJ, Bates I, editors. Dacie and Lewis practical hematology. 10th ed. Germany: Churchill livingstone elsevier; 2006. p. 25-54.

16. Ohashi T, Yamaki M, Pandav CS, Karmarkar MG, Irie M. Simple microplate method for determination of urinary iodine. Clin Chem. 2000;46(4):529-36.

17. Worwood M. Iron deficiency anemia and iron overload. In: Lewis SM, Bain BJ, Bates I, editors. Dacie and Lewis practical hematology. 10th ed. Germany: Churchill livingstone elsevier; 2006. p. 132-60.

18. Zimmermann MB, Hurrell RF. Nutritional iron deficiency. Lancet. 2007;370: 511-20.

19. Zimmermann MB, Jooste PL, Pandav CS. lodine-deficiency disorders. Lancet. 2008:372(9645):1251-62.

20. Mirmiran P, Golzarand M, Majem LS, Aziz F. Iron, iodine and vitamin A in the Middle East; a systematic review of deficiency and food fortification. Iranian J Publ Health. 2012;41(8):8-19.

21. Khatiwada S, Gelal B, Shakya PR, Lamsal M, Baral N. Urinary lodine Excretion among Nepalese School Children in Terai Region. Indian J Pediatr. 2015; doi: 10.1007/s12098-015-1755-x

22. Khatiwada S, Gelal B, Gautam S, Lamsal M, Baral N. lodine status among school children of remote Hilly regions of Nepal. Indian Pediatr. 2015;52(5): 436-7.

23. Khatiwada S, Gelal B, Tamang MK, Kc R, Singh S, Lamsal M, et al. lodized salt use and salt iodine content among household salts from six districts of Eastern Nepal. J Nepal Health Res Counc. 2014;12(28):191-4.

24. Chaudhari RK, Gelal B, Brodie DA, Baral N. Thyroid function and urinary iodine status in primary school age children of the hills and the plains of Eastern Nepal. Indian Pediatr. 2012:49(4):332-3.

25. Khatiwada S, Kc R, Sah SK, Khan SA, Chaudhari RK, Baral N, et al. Thyroid dysfunction and associated risk factors among nepalese diabetes mellitus patients. Int J Endocrinol. 2015;2015:570198. doi:10.1155/2015/570198. 
26. Khatiwada S, Kc R, Gautam S, Lamsal M, Baral N. Thyroid dysfunction and dyslipidemia in chronic kidney disease patients. BMC Endocr Disord. 2015; 15:65. doi:10.1186/s12902-015-0063-9.

27. Vanderpump MPJ. The epidemiology of thyroid disease. Br Med Bull. 2011; 99(1):39-51.

28. Zimmermann MB, Boelaert K. lodine deficiency and thyroid disorders. Lancet Diabetes Endocrinol. 2015;3(4):286-95.

29. Bremner AP, Feddema P, Joske DJ, Leedman PJ, Leary PC O, Olynyk JK, et al. Significant association between thyroid hormones and erythrocyte indices in euthyroid subjects. Clin Endocrinol (Oxf). 2012;76(2):304-11.

30. Banday TH, Bhat SB, Bhat SB, Shah N, Bashir S. To study prevalence of incipient iron deficiency in primary hypothyroidism. Int J Res Med Sci. 2014;2(2):472-5.

31. Refaat B. Prevalence and characteristics of anemia associated with thyroid disorders in non-pregnant Saudi women during the childbearing age: a cross-sectional study. Biomed J. 2015:38(4):307-16.

32. Akhter S, Naher ZU, Parvin S, Nahar K, Ali M, Bashar T, et al. The status of thyroid hormones in iron deficient patients in Bangladesh. Medicine today. 2012;24(1):1-4

33. Eftekhari MH, Keshavarz SA, Jalali M, Elguero E, Eshraghian MR, Simondon KB. The relationship between iron status and thyroid hormone concentration in iron-deficient adolescent Iranian girls. Asia Pac J Clin Nutr. 2006;15(1):50-5.

34. Yavuz O, Yavuz T, Kahraman C, Yesildal N, Bundak R. The relationship between iron status and thyroid hormones in adolescents living in an iodine deficient area. J Pediatr Endocrinol Metab. 2004;17(10):1443-9.

\section{Submit your next manuscript to BioMed Central and we will help you at every step:}

- We accept pre-submission inquiries

- Our selector tool helps you to find the most relevant journal

- We provide round the clock customer support

- Convenient online submission

- Thorough peer review

- Inclusion in PubMed and all major indexing services

- Maximum visibility for your research

Submit your manuscript at www.biomedcentral.com/submit 